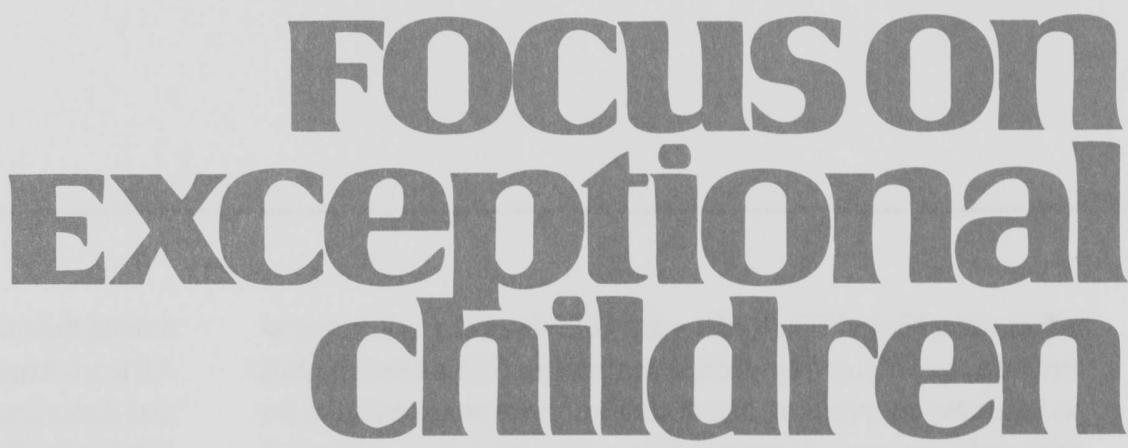

\title{
Using Prevention Strategies in General Education
}

\author{
Marjorie Montague, Jeanne Bergeron, and Ellie Lago-Delello
}

Recent emphasis on inclusion of students with disabilities in general education underscores the need for providing teachers with effective instructional strategies to accommodate children's diverse behavioral and learning needs (Hocutt, 1996). Inclusion asks that general and special education teachers exchange information about instructional strategies for students in special education who are mainstreamed for part of their school day in general education classrooms. Often, the intervention strategies that are effective for mainstreamed students are appropriate also as prevention strategies. Prevention programs are based on the premise that early identification of learning, behavioral, and emotional problems can lead to early intervention and better outcomes for children. If unchecked, the problems of young children may be exacerbated by environmental conditions in general education classes to a level where the only alternative, from the teacher's perspective, is placement in a special education program. If general education teachers feel competent in using prevention strategies and are able to see improvement in a child's behavior and learning, they may decide that referral to special education is unnecessary.

The purpose of this article is to describe classroom management, academic enhancement, and social development strategies that can be implemented in general education classrooms to prevent the development of serious emotional and behavioral problems in children. These strategies are part of a comprehensive intervention for elementary school children in the primary grades who were identified by their teachers as being at risk for having problems serious enough to warrant referral and placement in special education programs. The intervention is a component of Project SUCCESS, a 4-year research Project funded by the U. S. Department of Education.

In the first section of the article, we describe briefly the screening process that was used to identify children in kindergarten and first grade as being at risk for developing serious learning, behavioral, and emotional problems. In addition, we discuss the classroom dynamics within the student's general education classrooms to assist in understanding the quantity and quality of interactions between students and teachers and their perceptions of one another. The focus of the second section of the article is on several guiding principles for implementing prevention strategies. In the third section we present scenarios depicting typical classroom situations in which students' behavioral, academic, and personal/social problems are evident. These scenarios provide the framework for discussing how to select and implement prevention strategies that address specific problems of at-risk students in general

Marjorie Montague and Jeanne Bergeron are affiliated with the University of Miami. Ellie LagoDelello is an assistant professor at Florida Atlantic University, Boca Raton, FL. 
education classes. Finally, we set forth several recommendations for implementing prevention programs, and techniques to facilitate cooperation and collaboration among teachers for successful prevention programs.

\section{IDENTIFYING AT-RISK CHILDREN}

Project SUCCESS is a 4-year longitudinal study investigating the prevention of serious emotional disturbance in young children with behavioral and emotional problems. Project objectives included:

- identifying students at risk for developing serious behavioral and emotional problems who have not yet been referred for special education evaluation;

- developing comprehensive interventions for identified students;

- evaluating students annually to determine their behavioral, academic, and personal-social outcomes.

The project schools were selected purposefully because they had adopted a full-service school model and the ethnic composition of the 2,293-student population was representa-

\section{FOCuson Exceptional children}

ISSN 0015-511X FOCUS ON EXCEPTIONAL CHILDREN (USPS 203-360) is published monthly except June, July, and August as a service to teachers, special educators, curriculum specialists, administrators, and those concerned with the special education of exceptional children. This publication is annotated and indexed by the ERIC Clearinghouse on Handicapped and Gifted Children for publication in the monthly Current Index to Journals in Education (CIJE) and the quarterly index, Exceptional Children Education Resources (ECER). The full text of Focus on Exceptional Children is also available in the electronic versions of the Education Index. It is also available in microfilm from Xerox University Microfilms, Ann Arbor, MI. Subscription rates: Individual, $\$ 30$ per year; institutions, $\$ 40$ per year. Copyright ¿C 1997, Love Publishing Company. All rights reserved. Reproduction in whole or part without written permission is prohibited. Printed in the United States of America. Periodicals postage is paid at Denver, Colorado. POSTMASTER: Send address changes to:

$$
\begin{gathered}
\text { Love Publishing Company } \\
\text { Executive and Editorial Office } \\
\text { P.O. Box } 22353 \\
\text { Denver, Colorado } 80222 \\
\text { Telephone (303) } 757-2579
\end{gathered}
$$

Edward L. Meyen

University of Kansas
Glenn A. Vergason Georgia State University

Richard J. Whelan

University of Kansas Medical Center

\section{Stanley F. Love}

Publisher
Thomas Love

Associate Editor tive of the ethnic diversity of south Florida (7\% Anglo, $41 \%$ African-American and Haitian, 51\% Hispanic, and 1\% Asian and American Indian). The full-service school model is an effort by the State of Florida to address some of the characteristics associated with "high-risk" status that a significant number of the state's public school students and their families face. These characteristics include low socioeconomic status, physical/sexual abuse, substance abuse, neglect, homelessness, and medical complications.

\section{Screening}

For Project SUCCESS, the Systematic Screening for Behavior Disorders (SSBD) (Walker \& Severenson, 1992) was used to screen all kindergarten and first-grade students in two urban elementary schools in South Florida. The SSBD is a comprehensive, multiple-gated mass screening device for identifying elementary school students in general education classes who are at risk for developing serious behavioral and emotional problems. The screening process utilizes teacher judgment and direct observation and is accomplished in three stages. During the first year of Project SUCCESS, all kindergarten and first-grade students (numbering 628) at the two schools were screened.

Stage One. Teachers received a 1-hour workshop to become familiar with definitions of externalizing and internalizing behavior problems that children manifest. They identified 10 students in their classes as externalizers and 10 as internalizers. Then the teachers ranked the students as having the most to the least serious problems in each category.

Stage Two. The teachers completed the SSBD Critical Events Checklist and the Combined Frequency Index for Adaptive and Maladaptive Behavior, a rating scale, for each of the top five ranked externalizers and internalizers.

Stage Three. Project staff used the SSBD procedures for observing the academic engaged time of the children in the classroom and their peer social behavior on the playground.

As a result of the screening, three levels of risk status (low, moderate, and high) were assigned to students. The $103 \mathrm{stu}-$ dents identified as at moderate and high risk are receiving the classroom interventions described later in this article. The design of these interventions focused on teacher behaviors that seem to have an impact on their effectiveness, such as

— targeting teachers' negative attitudes toward students;

- increasing teachers' awareness of their behavior (e.g., feedback statements) that affect student behavior; and 
— increasing positive and corrective teacher feedback statements.

These and other aspects of classroom dynamics are discussed next.

\section{Classroom Dynamics}

During the second year of the project, the classroom environments were examined for the children identified as being at high risk for behavioral and emotional problems (LagoDelello, 1996). Research in classroom dynamics suggests that behavioral and academic outcomes both are mediated by interactions with classroom environments (Dudek, Strobel, \& Runco, 1993; Marshall, 1987; Stipek \& Daniels, 1988). Classroom dynamics include factors such as teacher attitudes toward and perceptions of students, student-teacher interactions, peer social interactions, classroom behavior, academic engaged time, students' perceptions of their teacher's expectations, and instructional accommodations to meet students' learning and behavioral needs.

A high-risk student, randomly selected from each of 13 firstand second-grade classes, was matched by gender, ethnicity, and language dominance with a not-at-risk classmate (a student who had not been ranked by the teacher in the previous year's screening). To examine teacher-student interactions, level of academic engaged time, and peer-social interactions, each student was observed independently by project staff on six different occasions. To learn about the types of instructional accommodations teachers make for students in their classes, individual interviews were conducted with the teachers. Finally, to investigate teacher and student attitudes and perceptions, teachers and students both completed rating scales.

\section{Teacher-Student Interactions}

Results indicated that the teachers rejected the at-risk students more than the not-at-risk students. The at-risk students also were perceived as having significantly fewer ideal pupil attributes than their not-at-risk peers. These findings are important because negative teacher attitudes toward and perceptions of students generally emerge within the first few weeks of school, tend to remain stable even after students display consistent improvements in behavior, and may affect their academic progress significantly (Safran \& Safran, 1985).

In addition, the at-risk students received significantly more teacher feedback statements than their not-at-risk peers. This feedback was more negative or neutral and nonacademic in nature than the feedback given to not-at-risk students. These findings support research in general education classrooms showing that students who conform less to normative standards of classroom behavior experience significantly more teacher rejection and negative teacher bias than the students who conform (Good \& Brophy, 1972; Kolb \& Jussim, 1994; Tal \& Babad, 1990; Wentzel, 1993). Given the complexities of the classroom environment, teachers may not be aware of their differential attitudes and behaviors toward students who are at-risk for behavioral, emotional, and learning problems in their classes. Effective classroom interventions for these children should be implemented early in the school year and should focus first on increasing teachers' awareness of their behavior toward children and then increasing teachers' positive and corrective feedback to the students.

\section{Academic Engaged Time and Instructional Accommodations}

Analysis of the classroom observations focusing on academic engaged time indicated that the at-risk students spent significantly less time academically engaged than their not-at-risk peers. Research suggests that students who are not engaged academically much of the time frequently become passive learners; give up easily on academic tasks; often become anxious, withdrawn, or angry about their school experience; and fail in later grades (Kolb \& Jussim, 1994; Skinner \& Belmont, 1993).

Despite general education teachers' positive regard for instructional and environmental accommodations, they often do not make modifications for children in their classes. Teachers of the at-risk students in this study most often thought that their classroom was not the appropriate placement for these students. They indicated that they accommodate students by giving one-to-one instruction when time permits, using peers to assist students who are having difficulty, changing seating arrangements, giving extra time and practice, and using verbal praise and tangible rewards. They saw changes in tasks, materials, and teaching style as unfeasible accommodations. In contrast, they saw changes in feedback procedures and practice opportunities as feasible.

Given the current emphasis on inclusion and provision of services within general education for students with special needs, teachers must become skilled in providing appropriate classroom interventions for these students. Modification of the classroom environment and instructional arrangements to increase the amount of time students spend academically engaged seems critical to promoting the success of these learners.

Strategies that could be implemented easily to increase academic engaged time for at-risk students include

- giving explicit and direct instructions before task assignment and ensuring that students know what to do;

- monitoring progress by providing frequent positive and corrective feedback during academic activities, reducing task requirements and assigning tasks commensurate with students' ability levels to increase the rate of task completion and academic success; and

- rewarding students for task completion. 


\section{Peer-Social Interactions}

In interactions among students, no significant differences between at-risk and not-at-risk students were found in the number of initiating or receiving interactions from peers during classroom activities. Also, both groups of students had positive academic self-perceptions and perceived their teachers as having positive academic expectations of them. The positive perceptions of all the students in this study were consistent with research that children's self-perceptions of competence are "close to maximum in early elementary grades" (Stipek \& MacIver, 1989, p. 521). The findings that the at-risk students were accepted socially by their peers are promising because social acceptance of peers seems to be a strong predictor of positive student outcomes (Wentzel, 1991).

Children who lack friends in school may feel isolated and rejected, often face serious social adjustment problems, and do not have the same opportunities to learn through peer support as their socially accepted peers (Asher \& Dodge, 1986; Weiner, 1987). Critical to the success of students atrisk for learning and behavioral problems is to help them maintain their positive self-perceptions, because negative attributions are associated with school failure (Weinstein, Madison, \& Kuklinski, 1995). Classroom interventions for these at-risk students should build on the positive peer interactions in the classroom through peer tutoring or cooperative learning activities.

In sum, several significant findings emerged from the investigation of classroom dynamics. The school had not yet identified the young at-risk students in this study as having learning, emotional, or behavioral problems serious enough to warrant placement in special education. Nevertheless, they were exhibiting behaviors in the classroom to the extent that their teachers behaved differently toward them compared to the not-at-risk students. These at-risk students were having experiences similar to students with disabilities in general education classrooms, such as:

- teacher rejection;

- low teacher expectations;

- negative and nonacademic teacher feedback;

- less academic engaged time; and

- few instructional accommodations to meet their learning and behavioral needs (Siperstein \& Goding, 1985).

These students, however, were accepted by their peers and seemed unaware of negative teacher attitudes, perceptions, and expectations. These results suggest a "window of opportunity" for effective classroom interventions that address students' learning and behavior problems by focusing on positive classroom interactions and successful learning experiences that could lead to better school outcomes for these children.

\section{GUIDING PRINCIPLES FOR USING PREVENTION STRATEGIES}

Based on our knowledge of classroom dynamics and the nature of interactions between at-risk students and their teachers and classmates, several principles for implementing prevention strategies in general education classrooms seem important. The following list of principles is not exhaustive; however, it gives teachers some structure as they implement strategies and evaluate their effectiveness. Because time and effort are at a premium for teachers and students alike, the strategies selected must be the most appropriate ones and yield the most benefits to students.

The principles focus on the following concerns: (a) accommodating differences in general education classrooms, (b) using functional assessment to identify student strengths and weaknesses, (c) using a positive approach in the classroom, (d) selecting the most appropriate and effective strategies, (e) deciding on individual, small-group, or whole-class strategies, and (f) monitoring the effectiveness of strategies.

\section{Accommodating Differences in General Education Classrooms}

Considerable evidence shows that general education teachers do little to accommodate the range of learner characteristics in their classes (Hocutt, 1996). Surprisingly, in one study, even teachers who had a high sense of general and personal teaching efficacy and were adjudged to be the most effective were found to be the least likely to accept students with maladaptive behavior or disabilities into their classes and did not feel responsible for dealing with students' problem behaviors (Walker \& Rankin, 1983). We know that students vary in their physical, psychological, and social-emotional attributes (cognitive ability, learning style, knowledge base, achievement, motivation, social behavior, and interests). To accommodate the range of students in their classrooms, teachers have to become aware of the diversity of students in their classroom, accept that their students have differences, and develop techniques and strategies that are effective in meeting the diverse needs of their students. Teacher responsibilities include developing skills in collaborating with team members and advocating for students, evaluating student progress so instruction can be modified if necessary, using proven strategies and curricula for teaching academic and personal/social skills, communicating effectively with students and families, and teaching students to generalize learned behaviors to other settings and situations (Gable, Laycock, Maroney, \& Smith, 1991).

\section{Assessing Student Behavior}

Effective prevention strategies depend on accurate analysis of a student's behavior to be able to target personal/social and academic behaviors that may be interfering with school 
success, and, if left unattended, may be exacerbated, leading to even more serious behaviors. Functional assessment is a systematic method for understanding and identifying these behaviors. The basic assumptions underlying this approach to assessment are (a) behavior is related to the context in which it occurs, and (b) behavior serves a specific function or purpose for the student, which makes performing that behavior gratifying in some way (e.g., getting attention, avoiding an unpleasant task). Foster-Johnson and Dunlap (1993) defined functional assessment as a "process whereby informed hypothesis statements are developed about relationships between events in the environment and the occurrence of a student's challenging behavior"' (p. 46).

Functional assessments provide information on the circumstances surrounding the behavior, the environmental conditions that may be supporting it, the function of the behavior, and the contextual variables that could be maintaining the behavior. When the causal or contributory contextual events are identified and the function of the behavior is determined, the teacher can think about altering the conditions to effect change in behavior or the function of the behavior by forming hypotheses about how these variations may affect the student's target behavior. In this way, intervention plans are developed that focus on specific behaviors and their functional significance.

\section{Using a Positive Approach}

The benefits of using positive reinforcement in classrooms are well acknowledged, and most teachers have at least a rudimentary understanding of the principles of reinforcement. Children with learning, behavior, and emotional problems typically receive more negative than positive feedback from teachers than other students do (Lago-Delello, 1996). Thus, teachers must realize the deleterious effects of negative feedback on children's classroom performance and self-esteem and provide a supportive classroom environment that creates many opportunities for students to receive positive reinforcement.

Verbal praise and positive feedback enhance students' intrinsic interest in tasks and activities (Cameron \& Pierce, 1994). Even more encouraging, however, is evidence that individuals continue to show intrinsic interest in their work even when the reinforcers are no longer present. One caveat, though, is the finding that rewards can have a negative impact on intrinsic motivation when they are offered simply for task completion without regard for standards of performance. Thus, teachers have to plan their reinforcement programs for students carefully and develop an incentive program that promotes successful performance rather than simply completion of a task.

\section{Selecting Appropriate and Effective Strategies}

Prevention strategies should be developed by articulating desired outcomes for students. Rather than focusing on prob- lem behaviors, the focus shifts to acceptable and desired behaviors that are realistically within reach for a specific child. In addition, appropriate and effective strategies are based on a functional assessment of a student's behavior with particular regard for the student's intent (i.e., "a student's behaviors have meaning for the student and are directed at achieving a desired outcome" (Cessna \& Borock, 1993, p. 55). Thus, the functional significance of the behavior is identified and the outcome behavior considers and reflects the desired outcome from the student's perspective (e.g., attention from peers, teacher attention, avoidance of a math task because the student lacks the skills).

When outcome behaviors are identified and coupled with an acceptable (replacement) behavior that will produce the desired outcome (e.g., being positively reinforced for staying on task for 15 minutes during reading group), strategies for attaining that desired outcome can be proposed. Then the conditions can be manipulated to allow the student to learn and practice acceptable behaviors while still attaining desired outcomes.

For example, the student who has difficulty staying on task during reading group should be assessed for reading achievement to determine if the group assignment is appropriate and, if so, could be positively reinforced for staying on task for 2-, then 4-, then 6-minute intervals until the limit is reached, which may be only a 10 -minute period. So the teacher learns the student is able to sustain attention for only 10 successive minutes during reading group. Understanding this dimension of the student's behavioral pattern enables the teacher to set the conditions so the group will have a 2-minute break after 8 minutes and then resume work for another 8 minutes.

\section{Deciding on Individual, Small-group, or Whole-class Strategies}

Several questions should be answered before deciding whether prevention strategies should be implemented with students individually either singly or within the context of a group, with small groups of students, or with an entire class. These questions have to do with the purpose and goals of the strategy, the resources and constraints of implementing the strategy, and the context in which the desired behaviors are to be performed.

First, what are the purpose and goals of the strategy? If the purpose is to increase an individual student's on-task behavior during reading group, the strategy could be implemented individually only with that student during group time. If the teacher desires, however, a reinforcement program could be instituted with the entire reading group while maintaining a focus on the target student. Most likely, though, the easiest approach in this example would be implementation with the target student only. In contrast, if the purpose is to improve the behavior of the class during transitions between the classroom and the cafeteria, it makes sense to design a strategy that is appropriate for the entire class. 
Second, what are the resources and constraints for implementing a strategy? For example, if an instructional aide, a classroom volunteer, or a peer is unavailable to work with an individual student on a one-to-one basis during math lessons, the strategy for the individual student may have to be modified so it can be consolidated into the class lesson. Rather than having a separate one-to-one instructional session for a student, the only alternative may be to adjust the assignment for the student within whole-class instruction.

Third, what is the context in which the desired behaviors are to be performed? For example, if the desired outcomes and behaviors have to do with reinforcement for appropriate social behavior on the playground, the social skills should be taught within the context of a small group and practiced on the playground during recess. Or if the target behavior is to keep one's hands to oneself while waiting in the cafeteria line, the strategy could be designed for an individual student and implemented in the cafeteria by enlisting the aid of a cafeteria worker or the supervising teacher.

\section{Evaluating the Effectiveness of Strategies}

Determining how well a strategy works for individual students is crucial to achieving desired outcomes and behaviors for students. The performance assessment model seems appropriate for monitoring student progress and evaluating the effectiveness of prevention strategies. This model fits with the trend toward authentic assessment of performance in general education. Authentic assessment means that skills and behaviors are assessed during real-life applications using real-life tasks in the context of real-life situations rather than simply judging a student's performance based on approximations of the task and context. According to Elliott (1994), performance assessments are "conceptually aligned with a behavior assessment model rather than a norm-referenced model" (p. 9). That is, it relies heavily on the use of direct observations and permanent products in evaluating behavior and depends on evaluating the behavior in authentic situations and settings. In addition, the interpretation is from an ideographic or criterion-referenced perspective, so the student is evaluated individually without reference to the performance of the group.

Several guidelines that have direct implications for developing authentic assessments of student performance were noted by Algozzine, Ruhl, and Ramsey (1991) in their model for curriculum-based assessment, as follows.

1. Specify the reasons for assessment, differentiating formative and summative evaluations to provide the most useful information for deciding what and how to teach skills and behaviors.

2. Analyze the curricula covering social and other functional curricula as well as academic curricula.
3. Formulate reasonable behavioral objectives for students based on functional assessments of behavior.

4. Develop appropriate assessment procedures using tests, direct observations, behavior rating scales, or other techniques to evaluate student performance.

5. Collect data in a well planned, systematic manner.

6. Summarize data using logical and sensible performance measures such as frequency counts, percentage correct, and so forth.

7. Display the data graphically using tables and charts to evaluate progress with respect to behavioral goals and objectives established previously.

8. Interpret the data and make decisions about what skills and behaviors to teach and how to teach them. Modify assessment methods if necessary.

In sum, teachers must become more aware of student differences in their classrooms and begin to accommodate the range of students, taking into consideration not only their weaknesses but their strengths as well. To facilitate accommodation and effective prevention of later behavioral, emotional, and academic problems of students, teachers can use functional assessment to identify student strengths and weaknesses, shift to a positive approach in the classroom, select the most appropriate and effective strategies based on assessment of student behavior and desired outcomes, decide on the feasibility and practicality of implementing the strategies and the conditions under which implementation would be most effective given the resources and constraints of the classroom and, finally, monitor the effectiveness of strategies using authentic assessment. Next we describe prevention strategies that are useful for managing classroom behavior, improving academic performance, and developing social skills.

\section{CLASSROOM MANAGEMENT STRATEGIES}

Classroom management is defined as the set of activities and strategies used to establish and maintain a classroom environment that enables the teacher to teach and the students to learn (Cooper, 1990). Effective classroom management, a fundamental component of the teaching-learning process, promotes active learning and good behavior in students (Walker, Colvin, \& Ramsey, 1995). Well defined procedures for performing tasks, clearly communicated expectations for student behavior, ongoing positive and corrective feedback, and fair and consistent treatment of students are other requisites for good classroom management (Reynolds \& Birch, 1988).

By monitoring their effectiveness in implementing these behaviors, teachers can create a classroom climate wherein all children can achieve success. The following scenarios show how two teachers became more effective classroom managers by using strategies that emphasize positive proce- 
dures for (a) making smooth transitions between classes and (b) creating a more meaningful and effective time-out.

\section{Making Smooth Transitions}

Ms. Henley, a first-grade teacher, tells her students to put away their things and line up to go to the cafeteria for lunch. About half of the 24 children make a mad dash for the door. The children at the front of the line are pushing each other and arguing about who will be the leader. Several girls toward the back of the group are talking. A few students still are putting their books away. Ms. Henley tells them to hurry and then turns to the children who are crowding at the door and says, "Do you call this a line? You need to stop talking and keep your hands to yourself" Ms. Henley opens the door and the children in the front of the group crowd into the corridor. The children in the back are behind the girls, who are so busy talking that they are not aware that the children in front of them have moved outside. Ms. Henley begins to lead the children down the stairs but then notices that several children are straggling behind, and she returns upstairs to retrieve them.

Transitions between academic activities and between physical spaces are times when behavior problems are likely to occur (Cangelosi, 1993). Therefore, specific procedures and expected behavior for performing smooth transitions have to be communicated clearly to the students. Even teachers who have well managed classrooms sometimes ask rhetorical questions such as, "Do you call this a line?" when acceptable line behavior is part of the students' behavioral repertoire.

Ms. Henley knew that her class was taking too long during transitions from one class to the next. She found herself reducing instruction time to allow extra time for the students to move between classes. Even with this extra time, her class often was late for special classes, thus reducing instructional time in those classes. She also was getting complaints from other teachers that her class was disturbing their classes during transitions. She needed a whole-class procedure that would make lining up and moving between classes quietly and quickly a positive experience for all of the children in her class. Ms. Henley chose the Dolphin Line strategy.

To introduce the Dolphin Line strategy, students first are shown the visual cue of four happy dolphins swimming in the ocean (see Figure 1). The teacher then guides the students as they brainstorm about the characteristics and behaviors of dolphins, with questions such as, "What are dolphins like?" and "What makes you think dolphins are friendly?" The teacher lists the responses on the chalkboard (e.g., smart, friendly, kind, mammals, graceful, fast, take care of each other, follow their leader, talk to each other, cooperative). Next, students are taught the undulating hand movement that simulates a dolphin swimming through the water. Students use their left hand, which frees their right hand for using the handrails on the stairs. Then they practice the dolphin hand movement while following a designated leader. During these activities, the teacher provides positive and corrective feedback, ensuring that all of the children understand what to do. Finally, the teacher reviews the cues and procedures for forming the Dolphin Line, and the class uses the strategy during each transition from the classroom to another area of the school. The teacher should continue to praise the students for being "good dolphins."

The prevention strategy of Dolphin Line solved the transition problem for Ms. Henley's class. Dolphin Line was de-

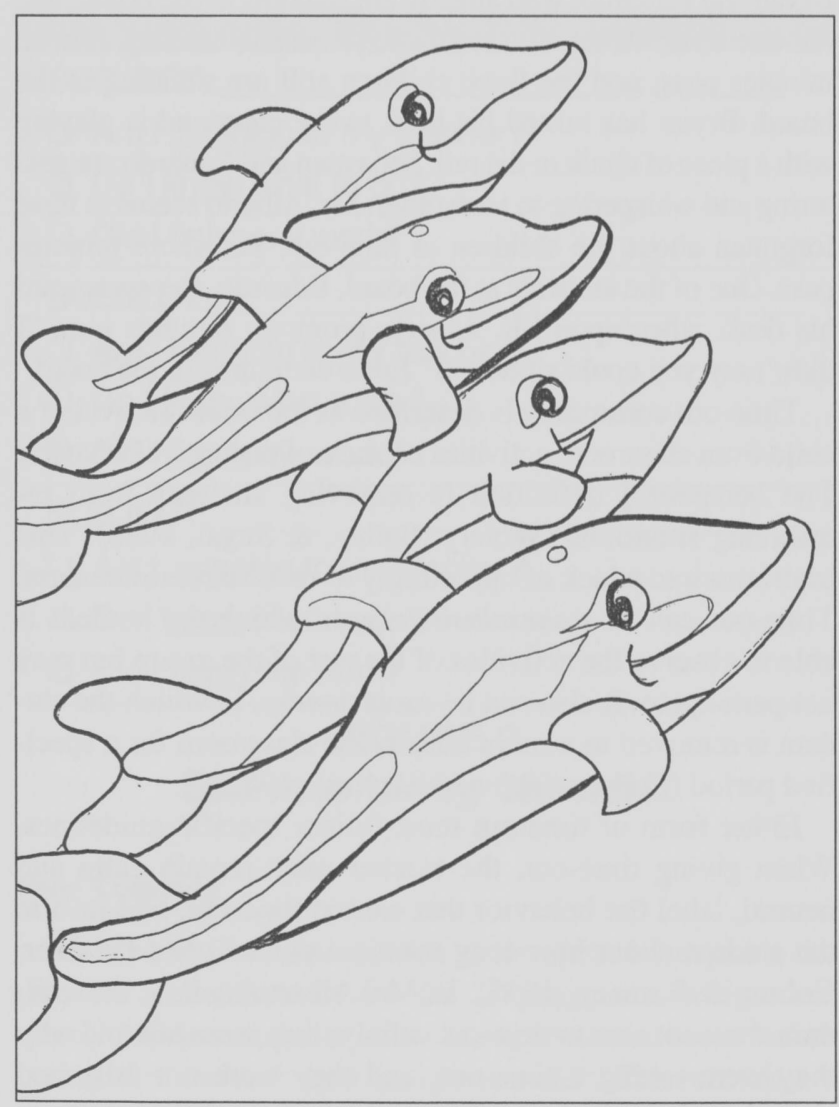

\section{FIGURE 1 \\ Visual Cue for Dolphin Lines Strategy}

signed to give students a positive focus for making transitions between physical environments. Students first were taught how to respond to the verbal and visual cues that precede forming the Dolphin Line. Then they were taught how to make a Dolphin Line. When the teacher holds up the dolphin picture and says, "Dolphin Line," the students now know they are to put away their materials and form a Dolphin Line behind the appointed leader. The leader starts the hand movement, and the students continue it throughout the transition. When the Dolphin Line is formed, the dolphin leader holds 
the classroom door open as the classmates "swim" out, and then takes the last place in line.

\section{An Effective Time-Out Procedure}

Mr. Alberto frequently raises his voice to control classroom behavior. Often he is heard using admonishments such as, "I've had it with you!" or "Go stand at the board until I say you can sit down!" Sebastian, a student with behavioral problems, often is sent to time-out. On this particular day, Sebastian talks out of turn and is sent to time-out. He joins two other children, Bryan and Eduardo, who already are standing at the board. Mr. Alberto turns his attention to the lesson he is teaching. Fifteen minutes pass, and the three children still are standing at the board. Bryan has turned his back to the class and is playing with a piece of chalk in the rail. Sebastian and Eduardo are gesturing and whispering to each other. Mr. Alberto seems to have forgotten about the children in time-out. Ten more minutes pass. One of the students at the board, Eduardo, moves toward his desk, whereupon Mr. Alberto promptly reminds him, "I didn't say you could sit down!" Eduardo returns to the board.

Time-out commonly is described as the brief removal of a child from classroom activities because of disruptive behavior. The behavioral definition is removing students from reinforcing situations (Wolery, Bailey, \& Sugai, 1988). This translates into a lack of opportunity to receive reinforcement. Time-out can be nonexclusionary, in which the student is able to observe the activities of the rest of the group but may not participate. It also can be exclusionary, in which the student is removed to a room outside the classroom for a specified period (Cooper, Heron, \& Heward, 1987).

Either form of time-out must follow specific guidelines. When giving time-out, the teacher must remain calm and neutral, label the behavior that earned time-out, and inform the student about how long the time-out will last (Walker, Colvin, \& Ramsey, 1995). In Mr. Alberto's class, the children were not sent to time-out calmly; they were not told why they were taking a time-out; and they were not informed about how long they were to remain there.

Time-out is controversial for several reasons, given by Henley, Ramsey, and Algozzine (1993) and Powell and Powell (1982):

1. It is a form of punishment.

2. Instructional time is lost during time-out.

3. Time-out can be a positive reinforcer for children who prefer time-out to doing the assignment.

4. Time-out may be more disturbing to the instructional flow of the class than the behavior that prompted the time-out in the first place.
Realizing that he had to modify his time-out procedure, Mr. Alberto began using the Remember the Rules strategy. This prevention strategy, he hopes, will assist children in following the classroom rules that he clearly defined for the students. The strategy is positive in that students learn the rules and are reinforced for following them by receiving positive notes to take home when they follow the rules. This strategy is based on the principle of positive reinforcement. That is, when children begin receiving positive reinforcement for following classroom rules, they will continue to do so even more and maintain improved performance with intermittent positive reinforcement (e.g., positive notes sent home).

To implement this strategy, Mr. Alberto identified the top three reasons for sending students to time-out: (a) leaving their seats without permission, (b) not listening to directions, (c) talking even when they are told to stop. These reasons became the basis for the following three classroom rules, phrased in a positive manner:

1. Stay in my seat unless I have permission to leave.

2. Listen to the teacher and follow directions.

3. Stop talking when the teacher tells me.

Next Mr. Alberto reviewed with the students the rules, the reasons for them, and the consequences for breaking the rules.

As a result, now when a student breaks a class rule, $\mathrm{Mr}$. Alberto can tell the student calmly which rule to remember. The child knows that the consequence is to go to the Remember the Rules area, write his or her name and the date on the paper provided, and then write the rule twice, using the laminated copy of the rules as a model. When the task is completed, the child takes the paper to the teacher and returns to his or her desk, and "time-out" is over. The key to this strategy is the reinforcement for following the rules. When a student (particularly a student who breaks the rules frequently) does not break a rule for a designated time (e.g., seatwork time or a morning), the teacher has to remember to send home a positive note to reinforce the child for following the class rules.

\section{ACADEMIC ENHANCEMENT STRATEGIES}

Children at risk for behavioral and emotional problems are vulnerable in a variety of school situations and, because of their problems, often do not develop the academic skills or the motivation and self-esteem necessary to succeed academically. The following academic enhancement strategies focus on positive procedures for (a) helping students become engaged in and completing academic tasks using a self-monitoring procedure, and (b) improving their reading and language arts skills using peer tutoring. The scenarios are presented to illustrate situations in which these strategies may be helpful in a general education classroom. 


\section{Self-Monitoring}

The children in Ms. Garcia's first-grade class are seated at long tables. Ms. Garcia has asked them to copy the spelling words from the chalkboard. Several children begin writing the words on lined primary paper. Other children are talking among themselves with no paper or pencil to complete the task. Mac has dropped his pencil and is crawling under the table to retrieve it. Frederick is seated with his back to the chalkboard and is peeling the paper off a crayon. Sarah is staring out the window, absentmindedly tapping the end of her pencil on her forehead. Mac comes out from under the table, but he does not have his pencil. He sits down in his chair and starts playing with a ruler on the table. Frederick still is peeling crayon wrappers. Sarah has begun to copy the spelling words. Ms. Garcia notices that several children are not doing the assignment and repeats the instruction. Many of the children who began the assignment when it was first given have finished and are waiting for further instructions.

J. M. Cooper (1990) defines self-monitoring as a strategy in which students record some aspect of their own behavior in order to modify that behavior. Self-observation increases the students' awareness of the target behavior. By teaching the students to use a simple checklist for increasing on-task behaviors and then rewarding their efforts, the students are guided toward the long-term goal of an intervention, which in this example, is self-management (Walker, Colvin, \& Ramsey, 1995).

Most of the children in Ms. Garcia's class were listening, knew what to do, and completed the assignment in a timely fashion. This was not the case for all of the children, though. Clearly, Ms. Garcia needed a more effective classroom management procedure to promote on-task behavior and facilitate effective and efficient instruction for all students in the class. She needed to gain the attention of all students before giving directions or beginning explanations. Otherwise, students develop the habit of not listening to the teacher and become dependent on repeated directions and explanations, which waste time and effort (Walker, Shinn, O'Neill, \& Ramsey, 1987).

The self-monitoring prevention strategy targets students who have difficulty getting and staying on task. This strategy is based on the notion that children can stay on task if they are cued to perform the simple steps and are reinforced systematically for performing the steps. Cues are verbal or nonverbal prompts or signals that trigger specific behaviors. This strategy enables children who have the academic prerequisites to complete the task to monitor themselves as they progress through the assignment.

The Self-Monitoring strategy consists of teacher cues, a student checklist (see Figure 2), and a systematic reinforcement chart. The three cues are designed to help the children direct their attention to the task at hand: (a) Am I listening to my teacher? (b) Do I know what to do? and (c) Did I finish my work? The teacher assists the students who have difficulty staying on-task by giving them verbal and visual cues that correspond to the three questions on the checklist. The children monitor their progress and are rewarded with stickers and positive notes to take home when they complete their work.

Name:

Date:

SUBJECT:

Am I listening to my teacher?

Do I know what to do?

Did I finish my work?

SUBJECT:

Am I listening to my teacher?

Do I know what to do?

Did I finish my work?

SUBJECT:

Am I listening to my teacher?

Do I know what to do?

Did I finish my work?

\section{FIGURE 2 Self-monitoring Checklist}

\section{Peer Tutoring}

Mr. Pearson has the attention of his class. He explains the purpose and directions for the language arts assignment clearly and demonstrates a few examples on the board before giving the students their assignment. Mr. Pearson takes a small group of children to the reading table for group reading. Monica eagerly begins working. Sam, seated next to Monica looks at the example on the board, and says, "This is hard." Monica looks up from her work and replies, "No it's not. It's easy." Sam asks her, "Well, how do you do it?" Monica retorts, "None of your beeswax!"

In this scenario, Sam had no resource for getting help other than interrupting the teacher or asking his classmates for help. Classmates often are excellent resources for helping other students, but they must understand that learning is a cooperative rather than a competitive endeavor and develop the skills and behaviors for giving good feedback to their classmates. Peer tutoring can be an ongoing function of all students in a classroom setting. 
Technically, peer tutoring is an instructional strategy in which students work in pairs as tutor and tutee or in teams in which team members take turns acting as teacher or tutor for the rest of the group. The goals of peer tutoring are to improve academic learning, develop cooperative work habits, and increase positive social interaction among students (Strayhorn, Strain, \& Walker, 1993). In addition to having positive outcomes for the students, peer tutoring has been found to be an intervention that does not overburden teachers; therefore they are more likely to use it (Walker, Colvin, \& Ramsey, 1995).

Peer tutoring takes place when one student who has learned the material helps another student who is working toward mastery. Peer tutors have to be trained in basic instructional procedures and techniques for providing reinforcement and corrective feedback. They also need training in identifying when to ask the teacher for help. The teacher must develop procedures for selecting and matching tutors and tutees and then supervise the tutoring sessions. The teacher essentially orchestrates the peer tutoring program, plans the instruction, and demonstrates the tutoring routine for the student teams. The tutor then works with the learner, providing assistance and feedback (Delquadri, Greenwood, Whorton, Carta, and Hall, 1986).

One positive consequence of peer assistance and peer tutoring programs is that at-risk students have a support system when the teacher is unavailable. Students who have academic difficulties are at even greater risk for school failure in a situation in which they are required to work independently while the teacher engages other children in the class in small-group work (Cooper \& Speece, 1991).

Studies of various methods to improve academic outcomes of elementary school students compared the variables of reduced class size, increased instructional time, computer-assisted instruction, and peer tutoring. The results showed that peer tutoring had the greatest effect on student learning and was the most cost-effective (Elliott, 1985; Levin, Glass, \& Meister, 1987). Other research on peer tutoring suggests that this strategy is effective in improving both tutees' and tutors' academic and social development (Cohen, Kulik, \& Kulik, 1982; Goodlad \& Hirst, 1989).

Students can be more effective tutors of their peers than adult tutors. Peers may have an easier time than adults relating to and understanding where the tutee is having problems because the student tutors are closer to the tutees cognitively (Cohen, 1986).

Peer-tutoring benefits tutees by adapting instruction to learners' pace, learning style, and level of understanding without comparing them to faster learners. It also gives tutees immediate feedback and correction. The extra attention and emotional support can help the tutee succeed. Tutors also benefit from reviewing material and having the opportunity to improve their thinking and communication skills (Fowler, 1986).

\section{SOCIAL DEVELOPMENT STRATEGIES}

Improving personal/social skills in young children at risk for developing serious emotional and behavioral problems is an educational priority (Zabel, 1991). These children need explicit instruction in personal and social skills for several reasons.

1. They frequently have attention problems that interfere with effective communication and social behavior (Javorsky, 1996).

2. They often receive more negative than corrective and positive feedback from adults in school and at home (Campbell, 1990; Lago-Delello, 1996).

3. They typically are poor observational learners and, therefore, do not attend to environmental cues to the same extent as other children (Hallenbeck \& Kauffman, 1995).

To illustrate, consider Marco, a student in an inner-city first-grade class. His teacher, Ms. Wilson, has observed that Marco seems confused about what to do much of the time, does not follow directions well, bothers the other children during class time, and does not participate readily in games and activities during recess. As part of the functional assessment, she had a parent volunteer maintain a narrative summary for about 3 hours during morning lessons, bathroom breaks, lunch line-up, and recess over a period of 2 days. Ms. Wilson trained the parent volunteer in writing narratives and also in collecting baseline data (usually frequency data).

The narrative revealed that, in addition to receiving reminders and reprimands from his teacher, Marco receives considerable negative attention from the other children for interrupting them during academic activities, pushing during transition times, and lagging when getting or putting away materials. Further, most of Marco's classmates ignore or ostracize him during recess.

Ms. Wilson decides to have the parent volunteer collect baseline data on the number of times Marco "pushes or shoves" other children and also record the number of negative verbal and nonverbal responses he receives from other children (including when the children ignore him). She then establishes two personal/social goals for Marco: (a) eliminate the pushing and shoving behavior, and (b) increase positive interactions between Marco and his classmates.

Next Ms. Wilson must decide which type of intervention to use to address these goals. Because Marco needs to improve his personal/social interactions, he must have the opportunity to interact in a positive manner with the teacher and with his classmates. To add this component to the already busy class agenda, she decides to form a group of six children. She schedules the social skills group to take place when eight of the 21 children are out of the classroom for ESOL instruction. From the 13 children who do not leave the room for 
ESOL instruction, she purposefully selects six children for the social skills group. The group includes Marco and two other children who, in her estimation, would benefit from social skills instruction and three children who are amicable and have relatively good social skills. She enlists the aid of the parent volunteer to monitor the remaining seven children. After reviewing several commercially available programs, Ms. Wilson decides to use A Collaborative Approach: Social Skills Instruction (Warger \& Rutherford, 1996).

First Ms. Wilson decides to teach the first-grade social skills that center on listening, cooperating with others, dealing with conflict, and feeling good about oneself. She follows the basic guidelines for implementing the social skills program and uses the five instructional strategies that are the core of the social skills instructional sequence. In this sequence, students are taught first to identify alternative prosocial behaviors and strategies. Then the teacher provides them with models demonstrating prosocial behaviors and strategies. Next students are given opportunities to practice prosocial behaviors in nonthreatening role-play or real-life situations. They are socially reinforced for demonstrating prosocial behaviors and strategies. Finally, students are taught how to control their behaviors through self-monitoring, self-evaluation, and self-reinforcement.

Performance-based assessment is used to monitor and evaluate student progress through direct observation of student behavior in a variety of situations and recording of the conditions under which the social skills are used, the frequency of their use, and the outcomes for the target students. Ms. Wilson has trained the classroom aide to do frequent observations of the three target students when they are interacting with the other students during a variety of school activities. Observational data are displayed on graphs to assist in the analysis of student performance. Students also are given homework assignments to practice social skills with siblings or adults in the home setting and complete simple forms to evaluate how well they did. Ms. Wilson will initiate a social skills home-school program to promote generalization of the learned social skills to other settings and situations.

\section{RECOMMENDATIONS FOR USING PREVENTION STRATEGIES}

Individual teachers can use prevention strategies effectively in their classrooms to achieve positive student outcomes. Outcomes for students may be even better, however, when the entire school is committed to prevention and creates a positive schoolwide learning environment for students who are at risk for problems. Administrators, teachers, and staff can work together to promote positive academic, behavior, and social/emotional outcomes for students.
The Child Study Team is a good vehicle for fostering collaboration and cooperation among school personnel. Typically, the team reviews results of data collected on the behavior of a student who is having problems in the classroom. Teacher reports, student grades and work samples, and classroom observations provide a picture of the student's performance in the classroom. Using these data, members of the Child Study Team can make recommendations for functionally assessing target behaviors and for implementing strategies to remedy current problems and prevent future problems.

Collaboration requires that team members develop interpersonal skills and technical skills of effective instruction (Warger \& Rutherford, 1993). Training in collaboration skills involves having team members "learn how to take joint ownership for problems and solutions, engage in joint decisionmaking, and share responsibility for implementing intervention" (p. 26). Training also may be necessary to develop teaching skills in unfamiliar domains such as classroom management, applied behavior analysis, and social/emotional development. For a successful schoolwide prevention program, teachers and other team members need sufficient time for planning, interacting with team members, and reflecting on and reviewing student outcome data.

Assessing student strengths as well as weaknesses is critical in planning appropriate prevention programs. By building on students' strengths and planning programs that are reinforcing from the outset, students become engaged and motivated. Prior to implementing any prevention strategy, it should be ascertained that students have the prerequisite skills to perform the behavior or complete the task. Prevention strategies should be implemented systematically and consistently for a given time before decisions are made regarding their efficacy. Efficacy of the prevention program for individual students can be determined only by closely monitoring and documenting the child's progress. If the strategy is not effective, those data will verify that result and the program will have to be modified or changed.

In addition, programs require adjustments throughout implementation, particularly with respect to reinforcement schedules. Teachers also must remember that the ultimate goal for students is self-reinforcement and intrinsic gratification. They must be taught how to evaluate their own behavior, recognize their strengths and areas for improvement, and reward themselves when they have done a good job.

\section{REFERENCES}

Algozzine, B., Ruhl, K., \& Ramsey, R. (1991). Behaviorally disordered? Assessment for identification and instruction. Reston, VA: Council for Exceptional Children.

Asher, S., \& Dodge, K. (1986). Identifying children who are rejected by their peers. Journal of Educational Psychology, 22, 444-449.

Cameron, J., \& Pierce, W. D. (1994). Reinforcement, reward, and intrinsic motivation: A meta-analysis. Review of Educational Research, 64, 
$363-423$.

Campbell, S. B. (1990). Behavior problems in preschool children. New York: Guilford Press.

Cangelosi, J. S. (1993). Classroom management strategies: Gaining and maintaining students cooperation. White Plains, NY: Longman.

Cessna, K. K., \& Borock, J. (1993). Instructionally differentiated programming: Suggestions for implementation. In K. K. Cessna (Ed.), Instructionally differentiated programming: A needs-based approach for students with behavior disorders, pp. 53-65. Denver: Colorado State Board of education.

Cohen, J. (1986). Theoretical considerations of peer tutoring. Psychology in the Schools, 23, 175-186.

Cohen, P. A., Kulik, J. A., \& Kulik, C. C. (1982). Educational outcomes of peer tutoring: A meta-analysis of findings. American Educational Research Journal, 19, 237-248.

Cooper, D. H., \& Speece, D. L. (1991). Maintaining at-risk children in regular education settings: Initial effects of individual differences and classroom environments. Exceptional Children, 57, 117-126.

Cooper, J. M. (Ed.). (1990). Classroom teaching skills (4th ed.). Lexington, MA: D. C. Heath and Co.

Cooper, J. O., Heron, T. E., \& Heward, W. L. (1987). Applied behavior analysis. Columbus, OH: Merrill.

Delquadri, J., Greenwood, C. R., Whorton, D., Carta, J. J., \& Hall, R. V. (1986). Classwide peer tutoring. Exceptional Children, 52, 535-542.

Dudek, S., Strobel, M., \& Runco, M. (1993). Cumulative and proximal influences on the social environment and children's creative potential. Journal of Genetic Psychology, 154, 487-499.

Elliott, E. (1985). Research has a significant impact on teaching and learning: Peer tutoring is most cost effective reform strategy. School Administrator, 42, 10-20.

Elliott, S. N. (1994). Creating meaningful performance assessments: Fundamental concepts. Reston, VA: Council for Exceptional Children.

Foster-Johnson, L., \& Dunlap, G. (1993). Using functional assessment to develop effective, individualized interventions for challenging behaviors. Teaching Exceptional Children, 25, 44-50.

Fowler, S. A. (1986). Peer-monitoring and self-monitoring; Alternatives to traditional teacher management. Exceptional Children, 52, 573-582.

Gable, R. A., Laycock, V. K., Maroney, S. A., \& Smith, C. (1991). Preparing to integrate students with behavioral disorders. Reston, VA: Council for Exceptional Children.

Good, T., \& Brophy, J. (1972). Behavioral expression of teacher attitudes. Journal of Educational Psychology, 63, 617-624.

Goodlad, S., \& Hirst, B. (1989). Peer tutoring. A guide to learning by teaching. New York: Nichols Publishing.

Hallenbeck, B. A., \& Kauffman, J. M. (1995). How does observational learning affect the behavior of students with emotional or behavioral disorders? A review of research. Journal of Special Education, 29, 45-71.

Henley, M., Ramsey, R. S., \& Algozzine, R. (1993). Characteristics of and strategies for teaching students with mild disabilities. Needham Heights, MA: Allyn \& Bacon.

Hocutt, A. (1996). The effectiveness of special education: Is placement the critical factor? Monographs of the Center for the Future of Children, 56. Los Altos, CA: Lucile Packard Foundation.

Javorsky, J. (1996). An examination of youth with attention-deficit/hyperactivity disorder and language learning disabilities: A clinical study. Journal of learning Disabilities, 29, 247-258.

Kolb, K., \& Jussim L. (1994). Teacher expectations and underachieving gifted children. Roeper Review, 17, 26-30.

Lago-Delello, E. (1996). Classroom dynamics and young children identified as at risk for the development of serious emotional disturbance. Unpublished doctoral dissertation, University of Miami, FL.

Levin, H., Glass, G., \& Meister, G. (1987). Cost-effectiveness of computerassisted instruction. Evaluation Review 11, 50-72.

Marshall, H. (1987). Motivational strategies of three fifth grade teachers. Elementary School Journal 88, 377-384.
Powell, T. H., \& Powell, I. Q. (1982). The use and abuse of using time-out procedure for disruptive pupils. Pointer, 26, 18-22.

Reynolds, M. C., \& Birch, J. W. (1988). Adaptive mainstreaming: A primer for teachers and principals (3d ed.). New York: Longman.

Safran, S., \& Safran, J. (1985). Classroom context and teacher's perceptions of problem behaviors. Journal of Educational Psychology. 77, 20-28.

Silberman, M. (1969). Behavioral expression of teacher attitudes toward elementary school students. Journal of Educational Psychology. 60, $402-407$.

Siperstein, G. N., \& Goding, M. (1985). Teachers' behavior toward LD and non-LD children: A strategy for change. Journal of Learning Disabilities, 18, 139-144.

Skinner, E., \& Belmont, M. (1993). Motivation in the classroom: Reciprocal effects of teacher behavior and student engagement across the school year. Journal of Educational Psychology, 85, 571-581.

Stipek, D., \& Daniels, D. (1988). Declining perceptions of competence: A consequence of changes in the child or in the educational environment? Journal of Educational Psychology, 80, 352-356.

Stipek, D., \& MacIver, D. (1989). Developmental changes in children's assessment of intellectual competence. Child Development, 60, 521-538.

Strayhorn, J., Strain, P. S., \& Walker, H. M. (1993). The case for interaction skills training in the context of tutoring as a preventative mental health intervention in the schools. Behavioral Disorders, 19, 11-26.

Tal, Z., \& Babad, E. (1990). The teacher's pet phenomenon: Rate of occurrence, correlates, and psychological costs. Journal of Educational Psychology, 82, 637-645.

Walker, H. M., Colvin G., \& Ramsey, E. (1995). Antisocial behavior in school: Strategies and best practices. Pacific Grove, CA: Brooks/Cole.

Walker, H. M., \& Rankin, R. (1983). Assessing the behavioral expectations and demands of less restrictive settings. School Psychology Review, 12, 274-282.

Walker, H. M., \& Severenson, H. (1992). Systematic screening for behavior disorders: Technical manual. Longmont, CO: Soporis West.

Walker, H. M., Shinn, M. R., O’Neill, R. E., \& Ramsey, E. (1987). A longitudinal assessment of the development of antisocial behavior in boys: Rationale, methodology and first year results. Remedial \& Special Education, 8, 7-16, 27.

Warger, C. L., \& Rutherford, R. B.(1993). Co-teaching to improve social skills. Preventing School Failure, 37, 21-27.

Warger, C. L., \& Rutherford, R. B.(1996). A collaborative approach: Social skills instruction. Ann Arbor, MI: Foundation for Exceptional Innovation.

Weinstein, R., Madison, S., \& Kuklinski, M. (1995). Raising expectations in schooling: Obstacles and opportunities for change. American Educational Research Journal, 32, 121-159.

Wentzel, K. (1993). Does being good make the grade? Social behavior and academic competence in middle school. Journal of Educational Psychology, 85, 357-364.

Weiner, J. (1987). Peer status of learning disabled children and adolescents: A review of the literature. Learning Disabilities Research, 2, 62-79.

Wolery, M., Bailey, D. B., \& Sugai, G. M. (1988). Effective teaching: Principles and procedures of applied behavior analysis with exceptional students. Needham, MA: Allyn and Bacon.

Zabel, M. K. (1991). Teaching young children with behavioral disorders. Reston, VA: The Council for Exceptional Children.

Preparation of this article was supported by Grant H237F40022 from the U. S. Department of Education, Office of Special Education Programs, Division for innovation and Development. Correspondence concerning this article should be addressed to Marjorie Montague, School of education, University of Miami, P.O. Box 248065, Coral Gables, FL 33124. Electronic mail may be sent via Internet to mmontague@umiami.ir.miami.edu. 